\title{
Non-Surgical Interventions for Hospitalized Adults with Class II or Class III Obesity: A Scoping Review
}

This article was published in the following Dove Press journal: Diabetes, Metabolic Syndrome and Obesity: Targets and Therapy

\section{Merridie Rees $\mathbb{D}^{1,2}$ \\ Clare E Collins $\mathbb{D}^{3}$ \\ Nienke De Vlieger ${ }^{3}$ \\ Vanessa M McDonald (D) ${ }^{1,2}$}

'John Hunter Hospital, Hunter New England Local Health District, Newcastle, NSW, Australia; ${ }^{2}$ Priority Research

Centre for Healthy Lungs and the School of Nursing and Midwifery, Faculty of Health and Medicine, University of Newcastle, Newcastle, NSW, Australia; ${ }^{3}$ Priority Research Centre for Physical Activity and Nutrition and the School of Health Sciences, Faculty of Health and Medicine, University of Newcastle, Newcastle, NSW, Australia

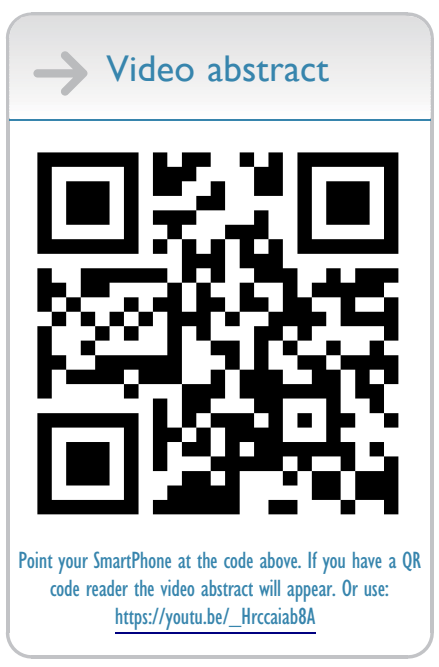

Correspondence: Vanessa M McDonald School of Nursing and Midwifery, The University of Newcastle, Locked Bag 1000, New Lambton, NSW, 2305, Australia

Tel +6I 240420146

Fax +6I 240420046

Email vanessa.mcdonald@newcastle.edu.au

\begin{abstract}
Adult inpatients with Class II or III obesity and comorbidities have a high health burden with frequent hospitalizations. Surgical risk and patient choice can be contraindications to bariatric surgery, which is considered the gold standard treatment. The best approach to non-surgical management for this adult inpatient group is currently unknown. The aim of this scoping review was to summarize current research in the inpatient setting. The unpublished literature and six electronic database searches identified 4,582 articles, with 12 articles (reporting on 10 studies) eligible and included. The literature on the interventions and their key components in the non-surgical care of the adult inpatient with Class II or III obesity were mapped identifying service provision successes and gaps. The articles reported on intensive lifestyle interventions, comparison of oxygen administration regimes, total parenteral nutrition regimens, and pre-surgical rapid weight loss. Study designs included evaluation $(n=1)$, before-after intervention studies $(n=3)$, and randomized/non-randomized controlled trials $(n=6)$. The classification of obesity as a chronic disease is not universal resulting in reduced inpatient treatment options. Recommendations for consumers, practitioner practice, health policy-makers and future research priorities are reported. Further research in the development of cost-effective inpatient models of care is indicated.
\end{abstract}

Keywords: patient care, acute care, obesity, rehabilitation, hospitalized, review

\section{Introduction}

The World Health Organization (WHO) defines obesity as a body mass index (BMI) greater than or equal to 30 kilograms per metre squared $\left(\mathrm{kg} / \mathrm{m}^{2}\right) .{ }^{1}$ Classes II (BMI $\left.\geq 35-39 \mathrm{~kg} / \mathrm{m}^{2}\right)$ and III (BMI $\geq 40 \mathrm{~kg} / \mathrm{m}^{2}$ ) obesity are considered clinically severe and/or morbid obesity. ${ }^{2,3}$ Obesity is an escalating public health problem. Globally, obesity rates have tripled since 1975, with $13 \%$ of adults (over 18 years of age) in 2016 (6.5 million people) considered to have obesity, with the WHO reporting 2.8 million global deaths annually directly attributed to obesity. ${ }^{4}$

In the United States of America (USA) and Australia, 50\% of adults have at least one chronic condition and $23-26 \%$ have two of more. ${ }^{5-7}$ In Australia, $45 \%$ of the arthritis and $53 \%$ of the diabetes burden is attributed to patients diagnosed with overweight or obesity, with Indigenous Australian adults 1.6-times more likely to be have obesity than non-Indigenous Australians. ${ }^{8}$ If the obesity trends continue at the current rate, the predicted direct and indirect costs for Australia's healthcare will be $\$ 87.7$ billion by $2025 .^{9}$ 
The most common obesity-related comorbidities are cardiovascular disease, Type II diabetes mellitus (T2DM), insulin resistance, dyslipidemia, hypertension, cholelithiasis, gastroesophageal reflux disease, osteoarthritis, asthma/respiratory disease, and some cancers. ${ }^{4,10,11}$ A Spanish primary care cross-sectional study $(n=40,010)$ demonstrated the degree of obesity increased the risk of co-morbidity, for example there was a $33 \%$ increase in the odds of having asthma in Class I obesity [OR (95\% CI) $=1.33(1.17-1.50)]$ and a $75 \%$ increase in Class III obesity [OR $(95 \% \mathrm{CI})=1.75(1.34-2.29)]^{12}$

Bariatric surgery is a treatment option which is considered the gold standard for the management of patients with Classes II and III obesity. ${ }^{13}$ However, surgical management of adults with obesity and severe co-morbidities is often contraindicated in patients with some medical, intellectual, psychiatric, behavioral, or social conditions if their surgical/ anesthetic risk is too high or they are unable to comply with the ongoing follow-up protocol. ${ }^{5,14-17}$ Patients also report a reluctance to undergo surgery. In a mixed-method survey of 105 adults with obesity ${ }^{18}$ only $33 \%$ of patients were interested in bariatric surgery and $16.2 \%$ had "mixed feelings" concerning surgery. The $50.5 \%$ not interested cited surgery risks $(69.1 \%)$ and potential side-effects $(57.1 \%)$ as barriers. ${ }^{18}$ Intensive lifestyle inpatient programs have demonstrated improved quality-of-life ${ }^{19,20}$ and greater weight $\operatorname{loss}^{20}$ at $1^{19}$ to $2^{21}$ years with age, weight loss at 12 weeks, baseline mental health quality-of-life, and occupational status identified as predictors of weight loss at 1 year. ${ }^{20}$

Patients with Class II or III obesity experience a higher healthcare burden secondary to higher 30-day hospital readmission rates, nosocomial infection management, and increased risk of clinical failure on discharge. ${ }^{22-26}$ Halilovac et al ${ }^{22}$ retrospectively evaluated the medical records of 106 hospitalized patients with cellulitis and/or subcutaneous abscess. They identified $\mathrm{BMI} \geq 40 \mathrm{~kg} / \mathrm{m}^{2}(\mathrm{OR}=4.10, P=0.002)$ as an independent risk factor for readmission. ${ }^{22}$ In a comparison study ${ }^{25}$ of two groups $(n=2,045)$ of surgical patients (aged 65-80 years) undergoing hip and knee surgery, colectomy, or thoracotomy surgeries across 47 hospitals, patients with obesity (mean BMI $40 \mathrm{~kg} / \mathrm{m}^{2}$ ) had greater odds of renal dysfunction: OR (odds ratio) $=2.05(95 \% \mathrm{CI}=1.39-3.05)$, wound infection: $\mathrm{OR}=1.64(1.21-2.21)$, urinary tract infection: $\mathrm{OR}=1.55 \quad(1.24-1.94)$, respiratory events: $\mathrm{OR}=1.44 \quad(1.19-1.75)$, and hypotension: $\mathrm{OR}=1.38$ (1.07-1.80). Additionally the 30-day readmission risk was greater: $\mathrm{OR}=1.38(1.08-1.77)$, as was length of stay and costs compared with patients without obesity, $\left(\mathrm{BMI}=20-30 \mathrm{~kg} / \mathrm{m}^{2}\right) .{ }^{25}$

Patients with obesity report embarrassment associated with hospital admission, describing their experiences as undignified and discriminatory. ${ }^{27-29}$ Poor attitudes of health professionals toward patients with obesity can result in less than optimal care. ${ }^{27,30}$ Reports of negative experiences and poorer outcomes are also supported by others using various methodologies. ${ }^{27-29,31}$

In 2014-2015 in Hunter New England Area Health Service in Australia, readmission rates within 28 days for patients over 50 years with Class II or III obesity and comorbidities requiring acute care was 37\% (unpublished data). Additionally failure of patients to attend follow-up appointments and/or continue with their care plan post-discharge was highlighted by staff. Staff and patients' expressed dissatisfaction with the system, evidencing the inefficiency and issues in the current practice.

Obesity is classified as a chronic disease by WHO, the European and North American Medical Associations, The Obesity Society, and the UK Royal College of Physicians. ${ }^{29,32-36}$ The Australian Government Department of Health and the Australian Medical Association, however, both consider obesity as a lifestyle condition, with related chronic diseases, rather than as an identified chronic disease. $^{7,35,37}$ Opie et $\mathrm{al}^{35}$ highlight the disadvantage this creates for Australians with obesity, as they are excluded from multidisciplinary structured and funded care plans that are available to patients with a designated chronic disease classification. $^{35}$

The increasing health burden of Classes II and III obesity is a global phenomenon, which some health services have yet to address. Porter et al. ${ }^{38,39}$ studied obesity within the older population and called for further research in this area. ${ }^{39}$ The guidelines for the non-surgical assessment and management of patients with Class II or III obesity are designed for the primary care setting. Therefore, the best approach to management for adults admitted to hospital with Class II or III obesity and comorbidities is not known.

\section{Aim}

The aim of this scoping review was to therefore map the current literature relating to interventions (and their features and formats) that specifically target the care of the adult inpatient with Class II or III obesity. 


\section{Methods}

We conducted a scoping review using the framework of Peters et al. ${ }^{40}$ The review protocol is included in the online supplementary information.

\section{Search Strategy}

A search of the Cochrane Library, the Johanna Briggs Institute databases, and Medline for systematic reviews of inpatient interventions for the non-surgical management of the adult inpatient with Classes II or III obesity with or without comorbidity was conducted and did not identify any current systematic reviews on this topic. The search strategy aimed to find both published and unpublished studies from 1990-2019 (27 December) written in English. The early date in the range was selected due to the advances in treatment for obesity from this time with advances in pharmacological interventions and the development of national guidelines in several countries. $^{41-44}$

The databases searched included:

MEDLINE(R) and Epub Ahead of Print, In-Process \& Other Non-Indexed Citations and Daily (Ovid)); CINAHL (EBSCO); EMBASE (Ovid); PsychInfo (Ovid); Cochrane Library; and Scopus. Figure 1 details the search terms used.

The search for unpublished studies included:

Mednar; Clinical Trials Registry (clinical-trials.gov); Theses from Australian Digital Theses Program and Dissertation and Abstracts and ProQuest; Australian NH\&MRC Guidelines, American Guidelines, New Zealand Guidelines, PROSPERO, Australian Policy online and Open Grey. A secondary search of the reference lists of all included studies was undertaken to identify further potentially relevant studies.

\section{Identification of the Research Questions}

The Population-Intervention-Comparison-Outcome-Study (PICO) ${ }^{45}$ method was used to identify the following research questions.

What are the non-surgical interventions used in inpatient settings for the care of the adult patient with Class II or III obesity?

What are the features of these interventions?

What is the format of these interventions?

What outcomes are measured within these interventions?

\section{Eligibility}

Studies which recruited adults (18 years of age or older) with Class II or III obesity receiving a non-surgical intervention in an inpatient setting were included. Quantitative, qualitative studies, systematic reviews including meta-analysis, and meta-synthesis were included. Studies with combined inpatient/outpatient settings and or non-surgical/surgical interventions were included if the results of the non-surgical inpatient components of the study were reported separately.

\section{Data Extraction from the Included Studies}

Data were extracted using an excel spreadsheet/data extraction tool and included specific details about the publication details, country, year, populations, comorbidities, concept, and context, study design, intervention, features, formats, findings, and outcomes. Initial data were extracted by MR and independently reviewed with further data extracted by NDV. Both authors then confirmed the data extraction. The interventions features and formats included the type of intervention, profession of intervention facilitator, intervention components, key outcomes of interest, and findings. Any disagreements between these two reviewers were resolved through consensus without the need for a third reviewer.

\section{Results}

\section{Citation Retrieval}

PRISMA flow chart ${ }^{46}$ (Figure 2) describes the study selection process from identification to inclusion.

\section{Study Country and Dissemination (Table I)} The included 12 articles ${ }^{4-58}$ reported on 10 studies published between 1997 and 2019 (October) with four $\operatorname{articles}^{47-49,53}$ reporting on two studies (Table 1).

\section{Study Designs, Settings, and Interventions (Tables I and 2)}

The study designs included randomized $(n=2) /$ nonrandomized controlled trials $(n=4)^{47-49,52-54,57,58}(\mathrm{n}=6$ involving eight articles), evaluation ${ }^{56}(\mathrm{n}=1)$, and before-after intervention studies ${ }^{50,51,55}(\mathrm{n}=3)$. Settings for six studies $^{51,52,54-56,58}$ were inpatient only, while four studies ${ }^{47-50,53,57}$ combined inpatient and community settings with repeat readmissions to the inpatient setting. Total length of stay for the inpatient setting ranged from $1.3^{57}$ to $17^{47}$ weeks for nine of the ten studies. ${ }^{47,49-51,53-55,57,58}$ Intensive lifestyle interventions, ${ }^{47-50,53,55,57,58}$ were used in six studies. The implementation of an inpatient intervention using a very 


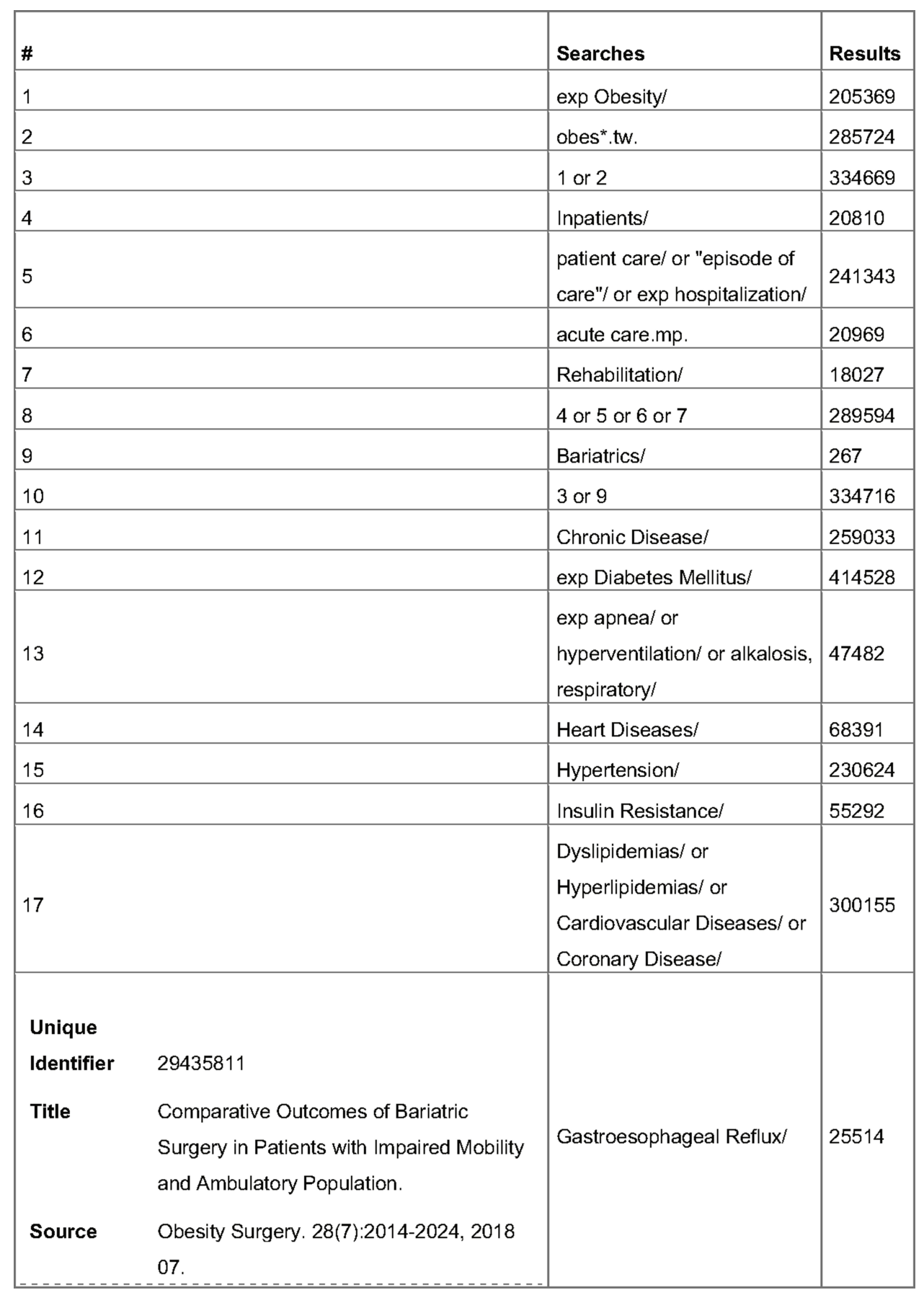

Figure I Medline Search.

low calorie diet (VLCD) for rapid weight loss prior to surgery to reduce the anesthetic/surgical risk, ${ }^{51,56}$ and acute medical interventions (a comparison of high flow and titrated oxygen therapy regimes ${ }^{52}$ and a comparison of isonitrogenic and hypoenergetic total parenteral nutrition (TPN) $)^{54}$ were used in two studies each (Table 1). The comparison of oxygen regimen study had an intervention period of 2.5 hours, ${ }^{52}$ while four studies ${ }^{47-50,53,57}$ had follow-up periods from 10 days ${ }^{57}$ to 5 years. ${ }^{47,48}$ Follow-up post-discharge from the inpatient stay was absent in six studies. ${ }^{51,-52,-54-56,58}$

Sample sizes of the studies ranged from $\operatorname{six}^{51}$ to $259,{ }^{58}$ with dropout rates ranging from $0 \%{ }^{55,56,58}$ to $46 \%{ }^{48}$ at 5 -year follow-up. Mean (SD) age of participants ranged from 28.5 $(7.2)^{50}$ to $\geq 60$ years. $^{56,58}$ Mean (SD) BMI of the studies ranged from $36(5)^{54}$ to $64.3(2.1) .{ }^{51}$ Obesity treatment was the primary reason for admission in eight articles, ${ }^{47-51,53,56,57}$ 


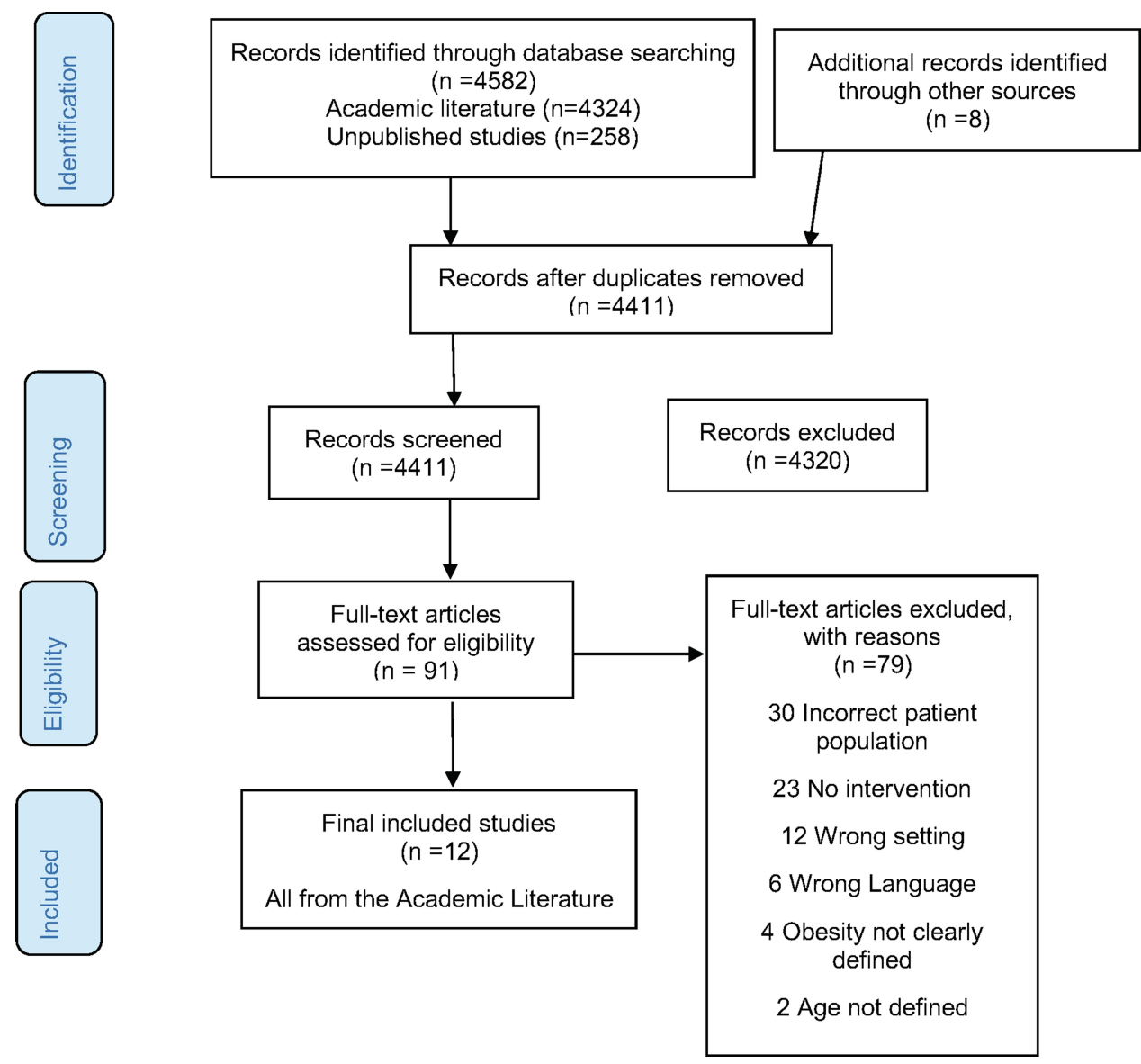

Figure 2 PRISMA flow chart ${ }^{46}$ showing citation process.

Note: PRISMA figure adapted from Moher D, Liberati A, Tetzlaff J, Altman D. Preferred reporting items for systematic reviews and meta analysis: the PRISMA statement. PLoS Med. 2009;6(7):el 000097.

rehabilitation for two articles, ${ }^{55,58}$ and acute care for two articles, ${ }^{52,54}$ (including cellulitis, ${ }^{52}$ asthma, ${ }^{52}$ respiratory infection, ${ }^{52}$ cancer, ${ }^{54}$ pancreatic disease, ${ }^{54}$ trauma,${ }^{54}$ and gastrointestinal disorders ${ }^{54}$ ) (Table 2).

\section{Profession of the Intervention Facilitator (Table 3)}

The clinical profession/professions of the person/s delivering the interventions was clearly defined in five studies, ${ }^{47,49,54,55,58}$ partially reported in two studies ${ }^{50,51}$ and not reported in three studies. ${ }^{52,56,57}$ Medical officers, ${ }^{47,49-51,54,55,58}$ nurses, ${ }^{47,49,54}$ physiotherapists, ${ }^{47,49,50,54,55,58 \quad \text { dietitians, or }}$ nutritionists, ${ }^{47,49-51,53,55,58}$ and psychologists ${ }^{47,49-51,53,55,58}$ were the disciplines who most frequently delivered interventions. Other disciplines reported were exercise physiologists, ${ }^{49,55}$ a pharmacist, ${ }^{54}$ a chef, and a social worker, ${ }^{47}$ with one study reporting clinical staff. ${ }^{57}$

\section{Description of Intervention Features and Formats}

The four studies without an intensive lifestyle intervention $^{51,52,54,56}$ and four of the studies with an intensive lifestyle intervention ${ }^{47,48,55,57,58}$ had structured interventions, while two of the intensive lifestyle intervention studies included elements of patient self-directed flexibility/choice within their interventions. ${ }^{49,50,53}$

Commonalities within the six intensive inpatient lifestyle intervention studies included combinations and variations of individual and group assessment and education sessions from medical officers, dietitians/nutritionists, physiotherapist/ exercise physiologists, and psychologists. ${ }^{47-50,53,55,57,58}$

\section{Interventions for the Acutely III Patient}

Only two of the studies aimed to improve management regimens of the acutely ill patient. ${ }^{52,54}$ Pilcher et $\mathrm{al}^{52}$ 
Table I Overview of Eligible Articles

\begin{tabular}{|c|c|c|c|c|c|}
\hline Author & Year & Country & Study Design & $\begin{array}{l}\text { Type of } \\
\text { Publication }\end{array}$ & Intervention \\
\hline Serafim et $\mathrm{al}^{56}$ & 2019 & Brazil & Evaluation & Journal Article & Nutritional Intervention \\
\hline Budui, et $\mathrm{al}^{58}$ & 2019 & Italy & $\begin{array}{l}\text { Non-randomised intervention comparative } \\
\text { study }\end{array}$ & Journal Article & Intensive lifestyle intervention \\
\hline Giordano, et $\mathrm{al}^{55}$ & 2017 & Italy & Pre and post intervention study & Journal Article & Intensive lifestyle intervention \\
\hline Pilcher, et $\mathrm{al}^{52}$ & 2017 & $\begin{array}{l}\text { New } \\
\text { Zealand }\end{array}$ & Randomized cross-over trial & Journal Article & Medical Intervention \\
\hline Danielsen, et $\mathrm{al}^{49}$ & 2013 & Norway & Clinical Control Trial & Journal Article & Intensive lifestyle intervention \\
\hline Martins, et al ${ }^{47}$ & 2010 & Norway & $\begin{array}{l}\text { Non-randomized intervention comparative } \\
\text { study }\end{array}$ & Journal Article & Intensive lifestyle intervention \\
\hline $\begin{array}{l}\varnothing \text { vrebø, et al }{ }^{48} \text { (Martins, et al } \\
\text { study) }\end{array}$ & 2017 & Norway & Longitudinal Outcome of & Journal Article & Intensive lifestyle intervention \\
\hline $\begin{array}{l}\text { Mæhlum, et } \text { al }^{53} \text { (Danielsen et al } \\
\text { study) }\end{array}$ & 2010 & Norway & Clinical controlled trial & Journal Article & Intensive lifestyle intervention \\
\hline Huerta, et $\mathrm{al}^{51}$ & 2009 & USA & Pre and post intervention study & Journal Article & Intensive lifestyle intervention \\
\hline Saldalamacchia, et $\mathrm{al}^{57}$ & 2008 & Italy & Non-randomized controlled trial & $\begin{array}{l}\text { Letter to the } \\
\text { Editor }\end{array}$ & Intensive lifestyle intervention \\
\hline Maffiuletti, et al ${ }^{50}$ & 2005 & France & Longitudinal clinical pre-post intervention study & Journal Article & Intensive lifestyle intervention \\
\hline Choban, et al ${ }^{54}$ & 1997 & USA & $\begin{array}{l}\text { Randomized, prospective, double-blind, } \\
\text { controlled trial }\end{array}$ & Journal Article & Medical Intervention \\
\hline
\end{tabular}

compared high flow oxygen delivery to titrated oxygen in patients without a pre-diagnosed obesity hypoventilation diagnosis, while Choban et al ${ }^{54}$ (in 1997) trialed hypoenergetic TPN compared to isonitrogenic TPN in acutely ill patients in the intensive care unit with the rationale that hypoenergetic TPN would prevent overfeeding and reduce the rate of nosocomial infection.

\section{Physical Activity Interventions}

A physical activity intervention component was included in five of the ten studies, ${ }^{47-49,53,55,57,58}$ with frequency of sessions ranging from once weekly, ${ }^{49,53,57}$ twice weekly, ${ }^{47,55,58}$ to more than twice weekly. ${ }^{53}$ The duration of each session was from 30 minutes, ${ }^{51}$ to 45 minutes, ${ }^{49}$ and 60 minutes. ${ }^{47,53,55}$ Activities included walking, ${ }^{49}$ aquatic, ${ }^{51}$ aerobic and gym exercises, including cycling and weights. ${ }^{50,55,58}$ Activity and education sessions were held face-to-face ${ }^{47,55,58}$ and included practical sessions. ${ }^{47,49,51,55,58}$ The aim of the physical activity intervention was to improve the inpatient's knowledge, skills in physical activity, and function, resulting in the individual continuing this behavioral change on discharge. $47,49,53,55,57,58$

\section{Dietary/Nutritional Interventions}

A dietary intervention component was included within nine of the ten studies. ${ }^{47,49-51,53-58}$ The content of the diet in Martins et $\mathrm{al}^{47}$ study was not described. Saldalamacchia et $\mathrm{al}^{57}$ reported limited dietary details $(800 \mathrm{kcal} /$ day for 3 months, $1,100 \mathrm{kcal} / \mathrm{day}$ for 3 months, and then 1,400 kcal/ day for 6 months). Maffuiletti et al ${ }^{50}$ reported the most detail related to the dietary intervention, including $\mathrm{kcal} /$ day intake, salt, macronutrient, and fluid intake. Low calorie (below $1,900 \mathrm{kcal} /$ day) and very low calorie diets (between $600-900 \mathrm{kcal} /$ day were used in seven of the studies, ${ }^{49-51,53,55,57,58}$ with one using a very low calorie $\operatorname{diet}^{51}$ as a liquid meal replacement. Very low calorie diets (VLCD) were used in five studies. ${ }^{51,55-58}$ Diets between $1,200-1,900 \mathrm{kcal} /$ day $^{49,50,53,55}$ were reported in three studies. The macronutrient composition of the diets was described in five studies, ranging from $20-21 \%$ protein, $50-60 \%$ carbohydrate, and $20-30 \%$ fat. ${ }^{49,50,53,55,56,58}$ Diets individualized to the patient by calculating individual basal metabolic rates and tailoring total daily energy targets accordingly were used in four studies. ${ }^{50,53,55,58}$ Huerta et $\mathrm{al}^{51}$ used a VLCD (liquid) providing $891 \mathrm{kcal} /$ day using a nutritional supplement, 
Table 2 Characteristics of Eligible Articles

\begin{tabular}{|c|c|c|c|c|c|c|c|c|c|}
\hline Author & $\begin{array}{l}\text { Sample } \\
\text { Size } \\
\text { Enrolled }\end{array}$ & $\begin{array}{l}\text { Sample } \\
\text { Size } \\
\text { Completed } \\
\text { (Drop-out) }\end{array}$ & $\begin{array}{l}\text { Mean Age } \\
\text { (SD) }\end{array}$ & $\begin{array}{l}\text { Mean } \\
\text { BMI } \\
\text { (SD) }\end{array}$ & $\begin{array}{l}\text { Inpatient } \\
\text { Setting } \\
\text { only }\end{array}$ & $\begin{array}{l}\text { Inpatient/ } \\
\text { Outpatient } \\
\text { Setting }\end{array}$ & Reason for Admission & $\begin{array}{l}\text { Inpatient } \\
\text { LOS } \\
\text { (Weeks) }\end{array}$ & $\begin{array}{l}\text { Follow } \\
\text { up } \\
\text { (Years) }\end{array}$ \\
\hline Serafim, et a $\left.\right|^{56}$ & 120 & 0 & $92 \% \leq 60$ years & $\begin{array}{l}53.7 \\
(0.39)\end{array}$ & Yes & No & Obesity treatment & 1 & 0 \\
\hline Budui, et al ${ }^{58}$ & 259 & 0 & $\begin{array}{l}48.2(11.5) \\
69.3(3.5)\end{array}$ & $\begin{array}{l}43.9 \\
(4.2)\end{array}$ & Yes & No & Rehabilitation program & 3 & 0 \\
\hline $\begin{array}{l}\text { Giordano, } \\
\text { et al }\left.\right|^{55}\end{array}$ & 136 & 136 & $\begin{array}{l}52.7 \\
(13.3)\end{array}$ & 43.2 & Yes & No & Rehabilitation program & 3 & 0 \\
\hline Pilcher, et $\mathrm{a}^{52}$ & 24 & $\begin{array}{l}22 \\
(8 \%)\end{array}$ & $53.5(16.1)$ & 50.4 & Yes & No & $\begin{array}{l}\text { Acute care- Cellulitis (6) } \\
\text { Asthma (7) Respiratory } \\
\text { Infection (2) Other (7) }\end{array}$ & $0^{g}$ & 0 \\
\hline $\begin{array}{l}\text { Danielsen, } \\
\text { et al }{ }^{49}\end{array}$ & 139 & $\begin{array}{l}104 \\
(25 \%)\end{array}$ & $\begin{array}{l}45.2(9.5)^{\mathrm{a}} \\
38.4(9.8)^{\mathrm{b}}\end{array}$ & $\begin{array}{l}42.6 \\
(5.2)\end{array}$ & No & Yes & Obesity treatment & 12 & 1 \\
\hline Martins, et $\mathrm{al}^{47}$ & 94 & $\begin{array}{l}83 \\
(12 \%)\end{array}$ & $\begin{array}{l}42(9.8)^{\mathrm{c}} \\
38.4(10.1)^{\mathrm{d}}\end{array}$ & $\begin{array}{l}45.4 \\
(5.6)\end{array}$ & No & Yes & Obesity treatment & $15-17$ & 5 \\
\hline $\begin{array}{l}\text { Ørebø, et al }{ }^{48} \\
\text { (Martins, et al } \\
\text { study) }\end{array}$ & 95 & $\begin{array}{l}44 \\
(46 \%)\end{array}$ & $\begin{array}{l}42(9.8)^{\mathrm{c}} \\
38.4(10.1)^{\mathrm{d}}\end{array}$ & $\begin{array}{l}45.3 \\
(5.5) \\
45.5 \\
(5.7)^{\mathrm{c}}\end{array}$ & No & Yes & Obesity treatment & $15-17$ & 5 \\
\hline $\begin{array}{l}\text { Mæhlum, et al }{ }^{53} \\
\text { (Danielsen et al } \\
\text { study) }\end{array}$ & 166 & $\begin{array}{l}108 \\
(36 \%)\end{array}$ & $42.1(10.6)$ & $\begin{array}{l}45.7 \\
(8.6)\end{array}$ & No & Yes & Obesity treatment & 16 & 1 \\
\hline Huerta, et $\mathrm{al}^{51}$ & 6 & $\begin{array}{l}5 \\
(17 \%)\end{array}$ & $\begin{array}{l}54.7(2.6)^{\mathrm{a}} \\
51.2(0.9)^{\mathrm{b}}\end{array}$ & $\begin{array}{l}64.3 \\
(2.1)\end{array}$ & Yes & No & Obesity treatment & 10 & 0 \\
\hline $\begin{array}{l}\text { Saldalamacchia, } \\
\text { et } \mathrm{al}^{57}\end{array}$ & 7 & 7 & $49(9)$ & - & No & Yes & Obesity treatment & 1.3 & $.027^{\mathrm{h}}$ \\
\hline $\begin{array}{l}\text { Maffiuletti, } \\
\text { et } \mathrm{al}^{50}\end{array}$ & 70 & $\begin{array}{l}64 \\
(9 \%)\end{array}$ & $\begin{array}{l}30.9(7.1)^{\mathrm{e}} \\
28.5(7.2)^{\mathrm{f}}\end{array}$ & $\begin{array}{l}41.3 \\
(4.3)\end{array}$ & No & Yes & Obesity treatment & 3 & 1 \\
\hline Choban, et a $\left.\right|^{54}$ & 30 & 30 & $\begin{array}{l}52(19) \\
52(15)\end{array}$ & $36(5)$ & Yes & No & $\begin{array}{l}\text { Acute Care -Cancer (II) } \\
\text { Pancreatic disease (I0) } \\
\text { Trauma (I) Gastrointestinal } \\
\text { issue (5) }\end{array}$ & 2 & 0 \\
\hline
\end{tabular}

Notes: ${ }^{\mathrm{a}}$ Intervention; ${ }^{\mathrm{b} C o n t r o l / c o m p a r a t o r ;}{ }^{\mathrm{C}}$ Residential intermittent program; ${ }^{\mathrm{W}}$ Weight loss camp; ${ }^{\mathrm{e}}$ Female; ${ }^{\mathrm{f}}$ Male; ${ }^{\mathrm{g}}$ Intervention 2.5 hours; ${ }^{\mathrm{h}}$ Follow-up 10 days. Abbreviations: SD, standard deviation; LOS, length of stay.

additional protein powder ( $83.7 \mathrm{gm} /$ day) and multivitamin supplements. Serafim et al ${ }^{56}$ reported use of a $600 \mathrm{kcal} /$ day VLCD with a similar macronutrient composition. Both studies $^{51,56}$ aimed for rapid weight loss to reduce anesthetic/surgery risks prior to the patient undergoing bariatric surgery. The aims of the other seven studies were to educate and upskill patients, enabling them to make healthier food choices following discharge. ${ }^{47,49,50,53,55,57,58}$ Choban et $\mathrm{al}^{54}$ used a hypoenergetic TPN formula providing 5,416 $\pm 1,250$ kilojoules/day, to isonitrogenic TPN 8,107 $\pm 828^{2}$ kilojoules/

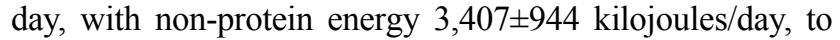
isonitrogenic TPN 6,308 $\pm 685^{2}$ kilojoules/day, and $120 \pm 27$ grams protein/day, compared to $108 \pm 14$ grams protein/day.

Interventions were delivered in a group only format in four studies, ${ }^{47,53,54,56}$ an individual patient format in one study, ${ }^{57}$ while four studies used a combination of group and individual intervention delivery. ${ }^{49-51,55,58}$ Frequency of intervention delivery was daily in five studies. ${ }^{50,53,55,57,58}$ In six studies nutrition interventions were provided in a structured format with only the 
Table 3 Profession/Discipline Intervention Delivered by

\begin{tabular}{|c|c|c|c|c|c|c|c|}
\hline Authors & $\begin{array}{l}\text { Medical } \\
\text { Officer }\end{array}$ & Nurse & Physiotherapist & $\begin{array}{l}\text { Exercise } \\
\text { Physiologist }\end{array}$ & $\begin{array}{l}\text { Dietitian / } \\
\text { Nutritionist }\end{array}$ & Psychologist & Other \\
\hline Serafim, et $\mathrm{al}^{56}$ & - & - & - & - & - & - & - \\
\hline Budui, et $\mathrm{al}^{58}$ & Yes & No & Yes & Yes & Yes & Yes & No \\
\hline Giordano, et al ${ }^{55}$ & Yes & No & Yes & Yes & Yes & Yes & No \\
\hline Pilcher, et $a^{52}$ & - & - & - & - & - & - & - \\
\hline Danielsen, et $\mathrm{al}^{49}$ & Yes & Yes & Yes & Yes & Yes & Yes & No \\
\hline Martins, et al $^{47}$ & Yes & Yes & Yes & No & Yes & Yes & Yes $^{a}$ \\
\hline $\begin{array}{l}\text { Mæhlum, et al }{ }^{53} \\
\text { (Danielsen et al study) }\end{array}$ & - & - & - & - & Yes & Yes & No \\
\hline Huerta, et $\mathrm{al}^{51}$ & Yes & - & - & - & Yes & Yes & No ${ }^{b}$ \\
\hline Saldalamacchia, et al ${ }^{57}$ & - & - & - & - & - & - & - \\
\hline Maffiuletti, et al ${ }^{50}$ & Yes & - & Yes & No & Yes & Yes & No \\
\hline Choban, et a $\left.\right|^{54}$ & Yes & Yes & No & No & No & No & Yes $^{c}$ \\
\hline $\begin{array}{l}\varnothing \text { vrebø, et } \mathrm{al}^{48} \text { (Martins, et } \\
\text { al study) }\end{array}$ & Yes & Yes & Yes & No & Yes & Yes & Yes $^{a}$ \\
\hline
\end{tabular}

Notes: -, Not Reported; ${ }^{\mathrm{a} S o c i a l}$ Worker and Chef; ${ }^{\mathrm{b}}$ Called Staff; ${ }^{\mathrm{C}}$ Pharmacist.

Danielsen et $\mathrm{al}^{49}$ study having a patient choice component with patients selecting a buffet breakfast and lunch and snacks as part of provision of the diet. Interventions were delivered face-to-face with a theoretical education component in six studies ${ }^{47,49,50,53,55,57,58}$ and a practical skills component in four studies. ${ }^{47,49,50,53}$

\section{Psychological Interventions}

A psychological intervention was included in five studies. ${ }^{47,49,50,53,55,58}$ A combined format of group and individual sessions were identified in four of these studies, ${ }^{47,53,55,58}$ while the Danielsen et $\mathrm{al}^{49}$ study used an individualized inpatient format. Patients were screened for psychiatric and eating disorders prior to enrolment in four studies. ${ }^{47-49,53,55,58}$ Frequency of the delivery of the patient intervention varied with individual sessions ranging from, twice to three times per week, ${ }^{50}$ to weekly, ${ }^{55,58}$ second weekly, ${ }^{47}$ and in one study on an ad hoc basis. ${ }^{49,53}$ The group sessions were held twice weekly, ${ }^{55,58}$ weekly, ${ }^{47}$ and second weekly. ${ }^{49}$ Duration of the sessions was poorly reported by most studies. ${ }^{47,48,53,55,58}$ However, Maffuiletti et $\mathrm{al}^{50}$ reported sessions to be 60 minutes in their study. All sessions were structured and face-to-face, with Martins et $\mathrm{al}^{47}$ the only study to report a practical component to the psychology sessions. The aim of the psychological interventions were to increase the patient's awareness of their eating behavior, increasing their ability to identify and manage their eating behavior, equipping them with an understanding of their needs for a lasting behavioral change required to ensure weight loss maintenance. ${ }^{47,49,53,55,58}$ The most commonly reported theoretical framework utilized for these interventions was Cognitive Behavioral Therapy, ${ }^{47,50,55,58}$ while two studies ${ }^{55,58}$ also utilized Prochaska and Clemente's trans-theoretical model and wheel of change.

\section{Key Study Outcomes of Interest (Table 4)}

Weight was the most common outcome measure and was included in eight of the 10 studies. ${ }^{47-51,53,55-58}$ Measurement of cardiovascular risk factors, ${ }^{47-50,55,58}$ symptoms of type II diabetes mellitus, ${ }^{47-49,51,55,58}$ physical activity change ${ }^{47-50,55,58}$ and psychological factors $^{47,49,51,55,58}$ were included in five studies, with body composition ${ }^{47-49,51,53,55,56,58}$ recorded in six. Nutrition-related outcomes from comparison of TPN, ${ }^{54}$ education on eating behaviors, food selection, and portion 
Table 4 Key Outcomes of Interest

\begin{tabular}{|c|c|c|c|c|c|c|c|c|c|}
\hline Author & $\begin{array}{l}\text { CVR } \\
\text { Factors }\end{array}$ & $\begin{array}{l}\text { Physical } \\
\text { Activity }\end{array}$ & Nutrition & Psychological & Medical $^{a}$ & DM 2 & Weight & $\begin{array}{l}\text { Body } \\
\text { Composition }\end{array}$ & Other \\
\hline Serafim, et $\mathrm{al}^{56}$ & No & No & No & No & Yes & No & Yes & Yes & Yes ${ }^{b}$ \\
\hline Budui, et $\mathrm{a}^{58}$ & Yes & Yes & Yes & Yes & No & Yes & Yes & Yes & No \\
\hline Giordano, et al ${ }^{55}$ & Yes & Yes & Yes & Yes & No & Yes & Yes & Yes & No \\
\hline Pilcher, et $\mathrm{al}^{52}$ & No & No & No & No & Yes & No & No & No & No \\
\hline Danielsen, et al ${ }^{49}$ & Yes & Yes & Yes & Yes & Yes & Yes & Yes & Yes & No \\
\hline Martins, et $\mathrm{al}^{47}$ & Yes & Yes & Yes & Yes & Yes & Yes & Yes & Yes & No \\
\hline $\begin{array}{l}\text { Mæhlum, et al } \\
\text { (Danielsen et al study) }\end{array}$ & No & Yes & Yes & Yes & No & No & No & No & No \\
\hline Huerta, et $\mathrm{al}^{51}$ & No & No & No & No & Yes & Yes & Yes & Yes & Yes ${ }^{b}$ \\
\hline Saldalamacchia, et $\mathrm{al}^{57}$ & No & No & No & No & No & No & Yes & No & No \\
\hline Maffiuletti, et al ${ }^{50}$ & Yes & Yes & Yes & No & No & No & Yes & No & No \\
\hline Choban, et al ${ }^{54}$ & No & No & Yes & No & No & No & No & No & No \\
\hline $\begin{array}{l}\varnothing v r e b \varnothing, \text { et al }{ }^{48} \\
\text { (Martins, et al study) }\end{array}$ & Yes & Yes & Yes & Yes & Yes & Yes & Yes & Yes & No \\
\hline
\end{tabular}

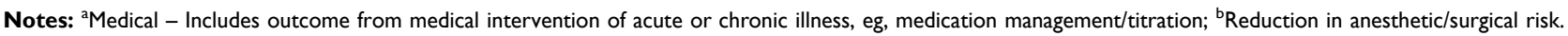

sizes were included in five studies, ${ }^{49,50,53,55,58}$ while diet related outcomes of resultant weight change were reported in eight studies. ${ }^{47-51,53,55-58}$ The efficacy of high flow oxygen administration (determined by $\mathrm{Ptco}_{2}$ at 60 minutes) comparison to titrated oxygen was the outcome of interest in the Pilcher et $\mathrm{al}^{52}$ study. Improvement in patients' overall chronic diseases evidenced by reduced medication dosages were reported in four studies. ${ }^{47-49,51,52}$

\section{Funding Sources}

Sources of funding were reported in five studies. ${ }^{47,50,52,54,58}$ Public health organizations funded two studies, ${ }^{47,54}$ a private research institute funded two, ${ }^{50,58}$ and one was funded by a public research council. ${ }^{52}$ Patient payments or reimbursements were not reported in any studies, one study reported the requirement for patients to take leave from work to attend the program. ${ }^{49,53}$

\section{Discussion}

This scoping review highlights significant knowledge gaps regarding effective approaches for the management of adults hospitalized with Classes II or III obesity, with or without comorbidities who are unsuitable for surgery. The small number of studies, and very limited number of RCTs identified emphasized the paucity of literature related to non-surgical interventions studies targeting improved identification and holistic management of this inpatient group.

In contrast there has been a strong focus in the literature on surgical interventions and strategies, including pre- and post-surgical care, ${ }^{60,61}$ management of complications, ${ }^{61}$ and reducing surgical risk; with 10 studies identified (only two were eligible for inclusion) targeting pre-surgical rapid weight loss. ${ }^{51,56}$

Of the studies that included structured intensive lifestyle inpatient programs, two studies ${ }^{49,50,53}$ incorporated some patient choice aimed at improving decision-making related to healthy choices to improve sustainability at home. In a mixed methods study within a community setting, Stead et $\mathrm{al}^{62}$ explored why some patients were better at making lifestyle change than others. Of the 148 participants in their study, ${ }^{62}$ a subgroup of 24 completed qualitative interviews. These interviews highlighted that lower levels of patient engagement due to physical and mental health problems resulted in lower weight loss. They suggest that in order to achieve successful patient outcomes vital program components must include holistic patient centered interventions that addressed patients' individual physical and mental health barriers to engagement. 
Our review suggests this is not the case and should be considered in the design of future interventions.

Semlitsch et al's ${ }^{63} 2019$ review of evidence-based practice guidelines for the management of obesity within high income countries identified key recommendations including; obesity being managed as a chronic disease, BMI recorded as a standard measurement, intensive lifestyle program duration of at least 6-12 months with interventions addressing behavioral changes, reduced total energy intake, and increased physical activity. They proposed that optimal follow-up of outcomes should be between 1-5 years and may need to continue indefinitely. ${ }^{63}$ Of the six intensive lifestyle studies included in this review $^{47-50,53,55,57,58}$ only one met all the above recommendations, ${ }^{47,48}$ while two studies met six out of the seven recommendations, ${ }^{49,50,53}$ one study met five recommendations, ${ }^{57}$ and two studies met three. ${ }^{55,58}$ Weimann et al $2019^{59}$ emphasized the importance of psychological support (for patients seeking the non-surgical approach) including 57 hours of cognitive-behavioral therapy (3.5 hours more than their exercise intervention and 13.5 more hours than their nutritional intervention) within a non-surgical intensive lifestyle community intervention. None of the intensive lifestyle interventions ${ }^{47-50,53,55,57,58}$ or the rapid weight loss intervention prior to surgery ${ }^{51,56}$ included pharmacological interventions. The absence of studies including pharmacological interventions suggest a gap in treatment options within the inpatient setting. These results highlight that whilst recommendations are available they have not been universally tested in intervention studies. RCTs testing these approaches are needed to ascertain their efficacy and cost-effectiveness both for the patient and health services.

The complexity of care for this population group may require recognition of Classes II and III obesity as a chronic disease and patient diagnosis, assessment, and management of obesity performed within the same framework as other chronic diseases such as respiratory, cardiovascular disease, or diabetes. Caterson et $\mathrm{al}^{29}$ conducted an online survey across 11 countries (including Australia) of patients with obesity $(n=14,502)$ and healthcare professionals $(\mathrm{n}=2,785)$, and reported that $68 \%$ of patients and $88 \%$ of healthcare professionals identified obesity as a chronic disease. However a significant barrier for the patient accessing care is the lack of communication and a disconnect between patients with obesity and their healthcare professionals, with neither group initiating discussion of obesity as a health issue within the same context as they would for other chronic diseases. ${ }^{29,64,65}$ When compared with outpatient groups, the inpatient groups and inpatient intermittent readmission studies, conducted within countries where Class II and III obesity are recognized as a chronic disease, achieved statistically significant improvements in health outcomes. ${ }^{47-49}$ Sarcopenic obesity is a challenge for the older adult with Class II or III obesity however, Budui et $\mathrm{al}^{58}$ reported weight loss in this older age group participants ( $>65$ years) with a reduction of frailty. Further research into the economic and health impacts of a models of care with combinations of age appropriate inpatient interventions followed by the intermittent residential lifestyle modification interventions with long-term follow-up for patients on the non-surgical pathway is indicated by the studies in this review. ${ }^{47-51,53,55-58}$

The majority of studies included in this review were from countries where obesity is considered a chronic disease (Norway, Italy, France, and the USA) ${ }^{47-51,53,55,57,58}$ There appears to be a disparity in the approaches to assessment and management of the patients with Class II or III obesity in these countries compared to countries that consider it a lifestyle condition. Norway, for example, offers obesity inpatient and outpatient clinics within its four health regions, and regional hospitals offer nonsurgical and surgical interventions. ${ }^{53}$ This is in contrast to Australia, where obesity is considered a lifestyle condition, and the majority of services for adult patients with Class II or III obesity are in the primary healthcare and private sector at a cost to the patient. ${ }^{43}$ Government funding is available in Australia for management of the common comorbidities that are associated with this level of obesity including cardiovascular disease, T2DM, and respiratory disease, but not for obesity assessment and management itself. ${ }^{66}$

The literature reports inadequate identification, diagnosis and treatment of overweight and obesity, ${ }^{67}$ unclear safe medication dosages, ${ }^{68}$ including disagreement on kidney function estimates for dosages and ongoing challenges to effective obesity care ${ }^{69}$ for this acute inpatient group. On admission to a hospital a patient's weight is considered as part of medication management and malnutrition screening and assessment. Within this review weight was a key outcome measure in six studies (reported in seven articles). ${ }^{47-49,51,55,56,58}$ However, these aspects of medical evaluation are commonly missed in the patient with Class II or III obesity. ${ }^{70,71}$ Unless a patient's weight immediately affects the management of their acute illness it is often not 
considered an important factor within their management care plan. ${ }^{71,72}$ Smoking and alcohol ${ }^{73}$ usage are routinely assessed on admission and interventions implemented; however, weight is not considered in the context of the same behaviours. ${ }^{71}$ Given the consequences of obesity rivalling health issues such as smoking and excessive alcohol usage the health professionals' holistic assessment of the patients care needs is incomplete without nutrition and weight related health assessments. A valuable opportunity to engage patients in education and self-management of obesity is missed. ${ }^{71}$ With studies showing patients with BMI $>40 \mathrm{~kg} / \mathrm{m}^{2}$ or a history of weight loss surgery have lower quality diets ${ }^{74}$ and nutrition knowledge gaps ${ }^{75}$ it is of concern that inpatient nutrition programs, healthy weight education, and appropriate interventions for achieving this are not always part of the inpatients' program. $^{71}$ Simple inpatient interventions such as increased flexibility within the range and availability of foods, menus, and patient choices could assist with healthy eating interventions. ${ }^{76}$ A systematic review of barriers to the identification, assessment, and holistic treatment of the acute and subacute inpatient with Class II or III obesity is indicated.

For sustained health benefits patients with Class II or III obesity require engagement in accessible programs with skilled multidisciplinary teams multifactorial intensive and long-term management and monitoring in a similar manner to other chronic diseases. ${ }^{63}$ The limited number of studies identified for this review highlight that there is currently a gap in non-surgical inpatient options for these patients outside Norway ${ }^{47-49,53}$ and Italy ${ }^{50,55,57,58}$ and demonstrates an under-researched area, particularly when contrasted with the prevalence of inpatients with Class II or III obesity. With adult inpatients with Class II or III obesity and their associated chronicity increasing in numbers a longer term view of their care within a chronic disease model is required. To overcome the evidence gaps clinicians need to partner with others and their patients locally, nationally and internationally to develop and test chronic disease interventions and models of care for this patient group for economic and healthcare efficacy.

\section{Strengths and Limitations}

A major strength of the current review is that it highlights the international variation in assessment, treatments, and outcomes for this patient group and the paucity of high quality research in this area. We also note some limitations, including the small number of studies identified for inclusion, the small sample sizes within these studies, and the lack of longitudinal data which limits definitive conclusions being drawn from the data. However, that was not the aim of this scoping review. As a scoping review, the quality of the studies is also not assessed, limiting generalization of results. This review also has additional strengths, as it represents studies conducted globally and importantly identifies research gaps that should be addressed for this vulnerable population.

\section{Conclusions}

Considering the global health impact of living with Class II or III obesity, including hospital admission/readmission rates, and evidence that not all patients with Class II or III obesity are eligible or willing to undertake a surgical treatment pathway, it is surprising there are so few studies published related to clinical care and treatment in this population group to date. This scoping review highlights that research, clinical practice, health service funding, and support are mainly focused around the surgical and primary healthcare interventions. Future research evaluating person centered models of care are required for this vulnerable population.

\section{Acknowledgments}

This scoping review was undertaken as part of a requirement for award of the degree of Doctor of Philosophy - Nursing (MR). Debbie Booth (Medical Librarian) University of Newcastle assisted with the electronic search identification of terms and strategies. Carolyn Van Leeuwarden (Hunter New England Local Health District Librarian) assisted with electronic searching. CEC is supported by a National Health and Medical Research Council of Australia Senior Research Fellowship. The authors thank Olivia Lewis, (Communications Officer - The Priority Research Centre for Healthy Lungs, the University of Newcastle) for the production of the video abstract.

\section{Disclosure}

Vanessa McDonald reports grants and personal fees from GSK and AstraZeneca for unrelated work. The authors report no other potential conflicts of interest for this work.

\section{References}

1. World Health Organisation. Obesity and overweight. World Health Organisation; Published 2015 [updated June, 2016]. Available from: http://www.who.int/mediacentre/factsheets/fs311/en/. Accessed May 1, 2016.

2. NCD Risk Factor Collaboration. Trends in adult body-mass index in 200 countries from 1975 to 2014: a pooled analysis of 1698 population-based measurement studies with $19 \cdot 2$ million participants. Lancet. 2016;387(10026):1377-1396. 
3. Zammit C, Liddicoat H, Moonsie I, Makker H. Obesity and respiratory diseases. Int J Gen Med. 2010;3:335-343.

4. World Health Organisation. Obesity and overweight. World Health Organisation; Published 2017. Available from: http://www.who.int/ mediacentre/factsheets/fs311/en/. Accessed January 24, 2018.

5. World Health Organization. Noncommunicable Diseases Progress Monitor. 2017.

6. Bauer U, Briss P, Goodman R, Bowman BA. Prevention of chronic disease in the 21 st century: elimination of the leading preventable causes of premature death and disability in the USA. Lancet. 2014;384:45-52.

7. Australian Health Ministers' Advisory Council. National Strategic Framework for Chronic Conditions. Health Do, editor. Canberra; 2017.

8. Australian Institute of Health and Welfare. A Picture of Overweight and Obesity in Australia 2017. Canberra: AIHW; 2017.

9. Porterhouse Coopers. Weighing the Cost of Obesity. 2015.

10. Bertakis KD, Azari R. Obesity and the use of health care services. Obes Res. 2005;13(2):372-379. doi:10.1038/oby.2005.49

11. Ambrose T, Cullen S, Baker G, et al. Obesity: a window of opportunity to intervene? Characteristics and management of morbidly obese adult inpatients in three trusts in Southern England. Clin Med. 2013;13(5):472-476. doi:10.7861/clinmedicine.13-5-472

12. Martin-Rodriguez E, Guillen-Grima F, Marti A, Brugos-Larumbe A. Comorbidity associated with obesity in a large population: the APNA study. Obesity Res Clin Pract. 2015;9(5):435-447. doi:10.1016/j. orcp.2015.04.003

13. Kumar RB, Aronne LJ. Review of multimodal therapies for obesity treatment: including dietary, counseling strategies, and pharmacologic interventions. Tech Gastrointest Endosc. 2017;19(1):12-17. doi:10.1016/j.tgie.2016.11.003

14. Ribaric G, Buchwald J, McGlennon TW. Diabetes and weight in comparative studies of bariatric surgery vs conventional medical therapy: a systematic review and meta-analysis. Obes Surg. 2014;24 (3):437. doi:10.1007/s11695-013-1160-3

15. Oreopoulos A, Kalantar-Zadeh K, Sharma A, Fonarow G. The obesity paradox in the elderly: potential mechanisms and clinical implications. Clin Geriatr Med. 2009;25(4):643-659. doi:10.1016/j. cger.2009.07.005

16. Agala RA, Almusaiad SM, Alsufi AM, et al. A critical review on risks versus benefits of bariatric surgery. Egypt J Hosp Med. 2017;66:279-284. doi:10.12816/0034664

17. Zenter A. Clinical assessment to determine a patient's suitability for bariatric surgery. B C Med J. 2018;60(3):151-155.

18. Wharton S, Serodio KJ, Kuk JL, Sivapalan N, Craik A, Aarts MA. Interest, views and perceived barriers to bariatric surgery in patients with morbid obesity. Clin Obes. 2016;6(2):154-160.

19. Danielsen KK, Sundgot-Borgen J, Mæhlum S, Svendsen M. Beyond weight reduction: improvements in quality of life after an intensive lifestyle intervention in subjects with severe obesity. Ann Med. 2014;46(5):273-282.

20. Karlsen TI, Sohagen M, Hjelmesaeth J. Predictors of weight loss after an intensive lifestyle intervention program in obese patients: a 1-year prospective cohort study. Health Qual Life Outcomes. 2013;11:165.

21. Martins C, Strommen M, Kulseng B. Longer length first stay in intermittent residential programmes is associated with larger weight loss at 1 and 2 years. Obes Facts. 2013;6(3):288-296.

22. Halilovic J, Heintz B, Brown J. Risk factors for clinical failure in patients hospitalised with cellulitis and cutaneous abscess. $J$ Infect. 2012;65:128-134.

23. Huttunen R, Karppelin M, Syrjanen J. Obesity and nosocomial infections. J Hosp Infect. 2013;85(1):8-16.

24. Puzniak L, Morrow LE, Huang D, Barreto J. Impact of weight on treatment efficacy and safety in complicated skin and skin structure infections and nosocomial pneumonia caused by methicillin-resistant staphylococcus. Clin Ther. 2013;35(10):157-1570.
25. Silber JH, Rosenbaum PR, Kelz RR, et al. Medical and financial risks associated with surgery in the elderly obese. Ann Surg. 2012;256 (1):79-86.

26. Gupta A, Richard L, Forsythe A. The humanistic and economic burden associated with increasing body mass index in the EU5. Diabetes Metab Syndr Obes. 2015;8:327-338.

27. Phelan SM, Burgess DJ, Yeazel MW, Hellerstedt WL, Griffen JM, van Ryan M. Impact of weight bias and stigma on quality of care and outcomes for patients with obesity. Obes Rev. 2015;16:319-326.

28. Lumley E, Homer C, Palfreyman S, Shackley P, Tod A. A qualitative study to explore the attitude of clinical staff to the challenges of caring for obese patients. J Clin Nurs. 2015.

29. Caterson ID, Alfadda AA, Auerbach P, et al. Gaps to bridge: misalignment between perception, reality and actions in obesity. Diabetes Obes Metab. 2019;21(8):1914-1924.

30. Nowicki T, Burns C, Fulbrook P, Jones J. Changing the mindset: an inter-disciplinary approach to management of the bariatric patient. Collegian. 2009;16(4):171-175.

31. MacDonald-Wicks LK, Gallagher LM, Snodgrass SJ, et al. Difference in perceived knowledge, confidence and attitudes between dietitians and other health professionals in the provision of weight management advice. Nutr Diet. 2015;72(2):114-121.

32. Stucki A, Daansen P, Fuessl M, et al. ICF core sets for obesity. $J$ Rehabil Med. 2004;36:107-113.

33. The Council on Science and Public Health. Is Obesity a Disease. 2013:3.

34. Allison DB, Downey M, Atkinson RL, et al. Obesity as a disease: a white paper on evidence and arguments commissioned by the council of the obesity society. Obesity (Silver Spring). 2008;16 (6):1161-1177.

35. Opie CA, Haines HM, Ervin KE, Glenister K, Pierce D. Why Australia needs to define obesity as a chronic condition. BMC Public Health. 2017;17:1-4.

36. Fastenau J, Kolotkin RL, Fujioka K, Alba M, Canovatchel W, Traina S. A call to action to inform patient-centred approaches to obesity management: development of a disease-illness model. Clin Obes. 2019;9(3):e12309-e12309.

37. Hohenester S, Christiansen S, Nagel J, et al. Lifestyle intervention for morbid obesity: effects on liver steatosis, inflammation, and fibrosis. Am J Physiol Gastrointest Liver Physiol. 2018;315(3): G329-G338.

38. Porter Starr K, Bales C. Excessive body weight in older adults: concerns and recommendations. Clin Geriatr Med. 2015;31(3):311-326.

39. Porter Starr KN, McDonald SR, Bales CW. Obesity and physical frailty in older adults: a scoping review of lifestyle intervention trials. J Am Med Dir Assoc. 2014;15(4):240-250.

40. Peters MDJ, Godfrey CM, Khalil H, McInerney P, Parker D, Soares CB. Guidance for conducting systematic scoping reviews. Int J Evd Based Hlthc. 2015;13(3):141-146.

41. Gunther S, Guo F, Sinfield P. Barriers and enablers to managing obesity in general practice: a practical approach for use in implementation activities. Qual Prim Care. 2012;20:93-103.

42. Bray GA, Fruhbeck G, Ryan DH, Wilding JP. Management of obesity. Lancet. 2016;387(10031):1947-1956.

43. National Health and Medical Research Council. Clinical Practice Guidelines for the Management of Overweight and Obesity in Adults, Adolescents and Children in Australia. Health AGDo, editor. Melbourne: National Health and Medical Research Council; 2013.

44. Turner LR, Harris MF, Mazza D. Obesity management in general practice: does current practice match guideline recommendations? Med J Australia. 2015;202(7):370-372.

45. Huang X, Lin J, Demner-Fushman D. Evaluation of PICO as a knowledge representation for clinical questions. AMIA Аnпи Sуmp Proc. 2006;359-363.

46. Moher D, Liberati A, Tetzlaff J, Altman D. Preferred reporting items for systematic reviews and meta analysis: the PRISMA statement. PLoS Med. 2009;6(7):e1000097. 
47. Martins C, Strommen M, Stavne OA, Nossum R, Marvik R, Kulseng B. Bariatric surgery versus lifestyle interventions for morbid obesity-changes in body weight, risk factors and comorbidities at 1 year. Obes Surg. 2011;21(7):841-849.

48. Ovrebo B, Strommen M, Kulseng B, Martins C. Bariatric surgery versus lifestyle interventions for severe obesity: 5-year changes in body weight, risk factors and comorbidities. Clin Obes. 2017;7(3):183-190.

49. Danielsen KK, Svendsen M, Maehlum S, Sundgot-Borgen J. Changes in body composition, cardiovascular disease risk factors, and eating behavior after an intensive lifestyle intervention with high volume of physical activity in severely obese subjects: a prospective clinical controlled trial. J Obes. 2013;2013:325464.

50. Maffiuletti NA, Agosti F, Marinone PG, Silvestri G, Lafortuna CL, Sartorio A. Changes in body composition, physical performance and cardiovascular risk factors after a 3-week integrated body weight reduction program and after 1-y follow-up in severely obese men and women. Eur J Clin Nutr. 2005;59:685-694.

51. Huerta S, Li Z, Anthony T, Livingston EH. Feasibility of a supervised inpatient low-calorie diet program for massive weight loss prior to RYGB in superobese patients. Obes Surg. 2010;20(2):173-180.

52. Pilcher J, Richards M, Eastlake L, et al. High Flow or titrated oxygen for obese medical inpatients: a randomised crossover trial. Med J Aust. 2017;27(10):430-434.

53. Mæhlum S, Danielsen KK, Heggebø LK, Schiøll J. The Hjelp24 NIMI Ringerike obesity clinic: an inpatient programme to address morbid obesity in adults. Br J Sports Med. 2012;46(2):91-94.

54. Choban PS, Burge JC, Scales D, Flancbaum L. Hypoenergetic nutrition support in hospitalized obese patients: a simplified method for clinical application. Am J Clin Nutr. 1997;66(3):546-550.

55. Giordano F, Berteotti M, Budui S, et al. Multidimensional improvements induced by an intensive obesity inpatients rehabilitation programme. Eat Weight Disord. 2017;22:329-338.

56. Serafim MP, Santo MA, Gadducci AV, Scabim VM, Cecconello I, de Cleva R. Very low-calorie diet in candidates for bariatric surgery change in body composition during rapid weight loss. Clinics (Sao Paulo, Brazil). 2019;74:e560.

57. Saldalamacchia G, Massaro P, Pacioni D, et al. Weight loss in obese type 2 diabetic patients on an intensive therapeutic programme: importance of an initial short hospitalization period. Nutr Metab Cardiovasc Dis. 2008;18(2):e1-2.

58. Budui S, Bigolin F, Giordano F, et al. Effects of an intensive inpatient rehabilitation program in elderly patients with obesity. Obes Facts 2019;12(2):199-210.

59. Weimann A, Fischer M, Oberänder Net al.. Willing to go the extra mile: Prospective evaluation of an intensified non-surgical treatment for patients with morbid obesity. Clin. Nutr., vol. 38, no. 4, pp,1773-1781. Aug2019. doi:10.1016/j.clnu.2018.07.027

60. Arafat M, Norain A, Burjonrappa S. Characterizing bariatric surgery utilization and complication rates in the adolescent population. J Pediatr Surg. 2019;54(2):288-292.

61. Ferraz AAB, Vasconcelos CFM, Santa-Cruz F, Aquino MAR, BuenosAires VG, Siqueira LT. Surgical site infection in bariatric surgery: results of a care bundle. Rev Col Bras Cir. 2019;46(4):e2252.
62. Stead M, Craigie A, Macleod M, et al. Why are some people more successful at lifestyle change than others? Factors associated with successful weight loss in the BeWEL randomised controlled trial of adults at risk of colorectal cancer. Int J Behav Nutr Phys Act. 2015;12 (1):1-12.

63. Semlitsch T, Stigler F, Jeitler K, Horvath K, Siebenhofer A. Management of overweight and obesity in primary care A systematic review of international evidence-based guidelines. Obes Rev. 2019;1-13.

64. Mold F, Forbes A. Patients' and professionals' experiences and perspectives of obesity in health-care settings: a synthesis of current research. Health Expect. 2013;16(2):119-142.

65. Gema F, Luca B, Dror D, et al. The ABCD of obesity: an EASO position statement on a diagnostic term with clinical and scientific implications. Obes Facts. 2019;12(2):131.

66. Health AGDo. Chronic disease management - individual allied health services under medicare - provider information. Australian Government Department of Health; Published 2019. Available from: https://www1.health.gov.au/internet/main/publishing.nsf/ Content/health-medicare-health_pro-gp-pdf-allied-cnt.htm. Accessed July 28, 2019.

67. Salazar-Sepúlveda LL, Villarreal-Pérez JZ. Impact of diagnosis of overweight and obesity on weight management among hospitalized patients. Obes Res Clin Pract. 2019;13(2):164-167.

68. Wong PJ, Pandya KA, Flannery AH. Evaluating the impact of obesity on safety and efficacy of weight-based norepinephrine dosing in septic shock: a single-center, retrospective study. Intensive Crit Care Nurs. 2017;41:104-108.

69. Srivastava G, Johnson ED, Earle RL, Kadambi N, Pazin DE, Kaplan LM. Underdocumentation of obesity by medical residents highlights challenges to effective obesity care. Obesity (19307381). 2018;26(8):1277-1284.

70. Flentje K, Knight C, Stromfeldt I, Chakrabarti A, Friedman N. Recording patient body weight in hospitals: are we doing well enough? Intern Med J. 2017;48.

71. Hossain MA, Amin A, Paul A, et al. Recognizing obesity in adult hospitalized patients: a retrospective cohort study assessing rates of documentation and prevalence of obesity. J Clin Med. 2018;7 (8):203.

72. Borel A-L, Schwebel C, Planquette B, et al. Initiation of nutritional support is delayed in critically ill obese patients: a multicenter cohort study. Am J Clin Nutr. 2014;100(3):859-866.

73. Higdon EA, Kimmons LA, Duhart BT, Hudson JQ. Disagreement in estimates of kidney function for drug dosing in obese inpatients. J Pharm Pract. 2019;32(1):41-47.

74. Harbury C, Collins CE, Callister R. Diet quality is lower among adults with a BMI $\geq 40 \mathrm{kgm}^{-2}$ or a history of weight loss surgery. Obes Res Clin Pract. 2019;13(2):197-204.

75. Harbury CM, Callister R, Collins CE. Nutrition "fat facts" are not common knowledge. Health Promot J Austr. 2018;29(1):93-99.

76. Naithani S, Whelan K, Thomas J, Gulliford MC, Morgan M. Hospital inpatients' experiences of access to food: a qualitative interview and observational study. Health Expect. 2008;11(3):294-303.

Diabetes, Metabolic Syndrome and Obesity: Targets and Therapy

Dovepress

\section{Publish your work in this journal}

Diabetes, Metabolic Syndrome and Obesity: Targets and Therapy is an international, peer-reviewed open-access journal committed to the rapid publication of the latest laboratory and clinical findings in the fields of diabetes, metabolic syndrome and obesity research. Original research, review, case reports, hypothesis formation, expert opinion and commentaries are all considered for publication. The manuscript management system is completely online and includes a very quick and fair peer-review system, which is all easy to use. Visit http://www.dovepress.com/testimonials.php to read real quotes from published authors. 